\title{
Quetiapine monotherapy in bipolar II depression: combined data from four large, randomized studies
}

\author{
Allan H Young ${ }^{1,13^{*}}$, Joseph R Calabrese ${ }^{2}$, Urban Gustafsson ${ }^{3}$, Michael Berk ${ }^{4,10,11,12}$, Susan L McElroy ${ }^{5,6}$, \\ Michael E Thase ${ }^{7}$, Trisha Suppes ${ }^{8}$ and Willie Earley ${ }^{9}$
}

\begin{abstract}
Background: Despite being present in up to $1 \%$ of the population, few controlled trials have examined the efficacy of treatments for bipolar II depression. Pooled data are presented from four placebo-controlled studies (BOLDER I [5077US/0049] and II [D1447C00135]; EMBOLDEN I [D1447C00001] and II [D1447C00134]) that evaluated the efficacy of quetiapine monotherapy for depressive episodes in patients with bipolar II disorder.

Methods: All studies included an 8-week, double-blind treatment phase in which patients were randomly assigned to treatment with quetiapine $300 \mathrm{mg} /$ day, quetiapine $600 \mathrm{mg} /$ day, or placebo. Outcome measures included the change from baseline in MADRS total score at week 8, effect sizes, and MADRS response and remission rates.

Results and discussion: Improvements in mean MADRS total scores from baseline to week 8 were significantly greater with quetiapine 300 and $600 \mathrm{mg} /$ day $(-15.58[n=283]$ and $-14.88[n=289] ; p<0.001)$ compared with placebo $(-11.61[n=204])$. The MADRS effect sizes were 0.44 for quetiapine $300 \mathrm{mg} /$ day and 0.47 for $600 \mathrm{mg} /$ day $(p<0.001$ vs placebo). Significantly higher proportions of patients receiving quetiapine, at both doses, than placebo-treated patients achieved response and remission at week $8(p<0.01)$. Common adverse events associated with quetiapine (both doses) included dry mouth, somnolence, sedation, dizziness, and headache. Rates of mania and hypomania were similar for quetiapine and placebo. Quetiapine monotherapy demonstrated significant efficacy compared with placebo and was generally well tolerated in the treatment of bipolar II depression.
\end{abstract}

Keywords: Bipolar II depression; Efficacy; Monotherapy; Quetiapine; Tolerability

\section{Background}

Using Diagnostic and Statistical Manual of Mental Disorders, Fourth Edition (DSM-IV) criteria, the reported lifetime prevalence of bipolar II disorder $(1.0 \%)$ is similar to the estimate for bipolar I disorder (1.1\%) (Merikangas et al. 2007). Moreover, sub-threshold bipolar II disorder has been estimated to affect up to $6.7 \%$ of the general population (Angst et al. 2010). The prevalence of bipolar II disorder in clinical practice may well be underestimated. Temporally, depression usually precedes hypomania (Berk et al. 2007). The recent BRIDGE study supports earlier observations that bipolar II disorder may be misdiagnosed as

\footnotetext{
* Correspondence: allan.young@kcl.ac.uk

'Department of Psychiatry, Imperial College, London SW7 2AZ, UK

${ }^{13}$ Centre for Affective Disorders, Institute of Psychiatry, King's College, London WC2R 2LS, UK

Full list of author information is available at the end of the article
}

major depressive disorder (Angst et al. 2012) and, in a large cohort study, at least $86 \%$ of patients whose diagnosis changed from major depressive disorder to bipolar disorder (i.e., approximately $10 \%$ of patients) had bipolar II disorder (Li et al. 2012). In another cohort study, $12.2 \%$ of patients had diagnoses changed from major depressive disorder to bipolar II disorder over a mean of 17.5 years (Fiedorowicz et al. 2011).

While the debilitating effects of bipolar I disorder are well established, the burden imposed by bipolar II disorder is gaining increasing recognition (Benazzi 2007; MacQueen and Young 2001; Valtonen et al. 2005). Among patients with bipolar II disorder, the risk of suicide, comorbidity, and role impairment is generally comparable with that of bipolar I disorder (Angst et al. 2010; Merikangas et al. 2011; Suppes and Dennehy 2002; 
Valtonen et al. 2005). The authors of the BRIDGE study have suggested that bipolar II disorder is even more pernicious than hitherto appreciated (Angst et al. 2011). They reported higher rates of comorbid anxiety in bipolar II disorder compared with bipolar I disorder and higher rates of anxiety disorders, eating disorders, substance use, suicide, and borderline personality comorbidity in bipolar II disorder than for unipolar disorder (Angst et al. 2011).

Depression is the prevailing phase of illness in patients with bipolar II disorder (Judd et al. 2003; Kupka et al. 2007). In a prospective study of treated patients, the percentage of time spent in depression was $37.0 \%$ for bipolar II disorder versus $36.0 \%$ for bipolar I disorder patients compared with $10 \%$ and $12.5 \%$ of the time with mania/hypomania, respectively (Kupka et al. 2007). The depression/mania ratios for patients with bipolar I and II disorder were of a similar magnitude, suggesting similar tendencies toward mood instability in the two groups. Depressive symptoms in bipolar disorder have a substantial impact on patients' quality of life and their ability to function in everyday activities (Rosa et al. 2010; Simon et al. 2007).

There has been a paucity of evidence regarding the treatment of bipolar II depression, and, in consequence, there are few consensus recommendations for the management of these patients (Swartz and Thase 2011). Older guidelines have generally adapted recommendations for bipolar I disorder, although more recent guidelines have considered bipolar II depression separately using the extant evidence base (American Psychiatric Association 2002; Goodwin 2003, 2009; Grunze et al. 2010; Keck et al. 2004; Yatham et al. 2013). Emerging reports support the effectiveness of several therapies in the treatment of acute bipolar II depression (Cruz et al. 2010; Swartz and Thase 2011). Among these agents is quetiapine, which is the only medication approved by the United States Federal Drug Administration for monotherapy of both bipolar I and II disorder depressive episodes (Seroquel Prescribing Information 2012).

The antidepressant efficacy of quetiapine monotherapy (300 and $600 \mathrm{mg} /$ day) in bipolar I and II depression was established in two pivotal, 8-week, placebo-controlled clinical trials, BOLDER (BipOLarDepRession) I and II (Calabrese et al. 2005; Thase et al. 2006). These findings were subsequently confirmed in the similarly designed EMBOLDEN (Efficacy of Monotherapy Seroquel in BipOLarDepressioN) I and II trials (McElroy et al. 2010; Young et al. 2010).

The efficacy of quetiapine in patients with bipolar II depression has been previously reported in a pooled analysis of the BOLDER I and II studies (Suppes et al. 2008). The comparable design of the BOLDER and EMBOLDEN trials facilitated a pooling of the data for patients with bipolar II depression data to increase the power of the statistical analyses. In the findings reported herein, the pooled data from all four studies are used to evaluate the efficacy of quetiapine (300 and $600 \mathrm{mg} /$ day) monotherapy in patients with bipolar II depression.

\section{Methods \\ Study design}

This was a pooled analysis of a subpopulation of patients with bipolar II depression from four randomized, multicenter, double-blind, fixed-dose monotherapy studies of quetiapine versus placebo in bipolar I or II depression (BOLDER I: 5077US/0049, $N=542$, patients with bipolar II depression: $n=182$; BOLDER II: D1447C00135, $N=509$, $n=171$; EMBOLDEN I: D1447C00001, $N=802, n=303$; and EMBOLDEN II: D1447C00134, $N=740, n=262$ ). The studies were conducted at sites across the USA (BOLDER I and II) or at centers across the USA, Canada, and elsewhere, including sites in Europe, Asia, Turkey, Central and South America, South Africa, and Australia (EMBOLDEN I and II). All studies adhered to the current amendment of the Declaration of Helsinki and the International Conference on Harmonisation/Good Clinical Practice guidelines. Prior approvals of the study protocols and amendments were received from either a central institutional review board or a review board at the study site. Written informed consent was obtained from all patients prior to study participation.

Details on the study design have been reported previously (Calabrese et al. 2005; McElroy et al. 2010; Thase et al. 2006; Young et al. 2010). Briefly, the design of each of the four studies encompassed 8 weeks of double-blind treatment whereby patients were randomized to receive quetiapine (300 or $600 \mathrm{mg}$ /day) or placebo. Additionally, the EMBOLDEN studies included the active comparators, lithium 600 to $1,800 \mathrm{mg} /$ day (EMBOLDEN I) or paroxetine $20 \mathrm{mg} /$ day (EMBOLDEN II) to gauge assay sensitivity (i.e., comparison vs placebo). Data from these active treatment groups have been reported previously (McElroy et al. 2010; Young et al. 2010). A continuation phase of 26 to 52 weeks' duration also formed the design of the EMBOLDEN studies, the results for which have been reported previously (Young et al. 2012). Randomization in the studies was achieved using an interactive voice-response central randomization system, and numbers were not sequential within a site. No member of the investigational teams had access to the randomization schemes during the conduct of the studies. All treatment packaging was identical, with placebo and active tablets identical in appearance and number.

\section{Patient population}

Eligible patients were adult outpatients aged between 18 and 65 years with a diagnosis of bipolar I or II disorder, 
most recent episode depressed as defined by DSM-IV (American Psychiatric Association 2000), with or without a rapid-cycling course ( $\geq 4$ episodes to $\leq 8$ episodes per year). Only patients with bipolar II disorder were included in the current analysis. Study participants were also required to have a Hamilton Rating Scale for Depression (Hamilton 1960) (HAM-D) total score $\geq 20$, a HAM-D item 1 (depressed mood) score $\geq 2$, and a Young Mania Rating Scale (Young et al. 1978) (YMRS) score $\leq 12$.

The key exclusion criteria in the four studies were a current depressive episode $>12$ months' or $<4$ weeks' duration at enrollment; an Axis I disorder diagnosis other than bipolar disorder; $\geq 8$ mood episodes in the preceding 12 months (except BOLDER I); a HAM-D Item 3 score $\geq 3$, posing a serious suicidal or homicidal risk (as judged by the investigator), or attempted suicide within the past 6 months. In addition, a history of nonresponse to an adequate treatment period (6 weeks) with $\geq 2$ classes of antidepressants during the current episode or previous nonresponse to the study treatments (as determined by the investigator); substance dependence $(D S M-I V)$ or abuse; or a clinically relevant medical condition led to exclusion from the study.

Current antipsychotic, antidepressant, and moodstabilizing medications were discontinued in a washout period of at least 5 to 28 days. In each study, patients were randomly assigned to once-daily quetiapine or matching placebo, which was administered orally at bedtime. An initial quetiapine dose of $50 \mathrm{mg} /$ day was subsequently increased in 100-mg increments to achieve a final target dose of 300 or $600 \mathrm{mg} /$ day at day 4 or day 8 , respectively. Concomitant treatment with all other psychotropic drugs was prohibited during the study, with the exception of hypnotics (zolpidem tartrate up to $10 \mathrm{mg} /$ day [all studies] and zaleplon up to $20 \mathrm{mg} /$ day, zopiclone up to $7.5 \mathrm{mg} / \mathrm{day}$, or chloral hydrate up to $1 \mathrm{~g}$ /day [EMBOLDEN I and II]) at bedtime for insomnia and lorazepam (up to $3 \mathrm{mg} /$ day) for severe anxiety. Hypnotics and lorazepam were permitted for the first 3 weeks of treatment, except in the $8 \mathrm{~h}$ before a psychiatric assessment.

\section{Efficacy assessments}

The primary efficacy outcome measure in all four studies was the change from baseline to week 8 in Montgomery-Åsberg Depression Rating Scale (MADRS) total score (Montgomery and Asberg 1979), and this is consequently utilized in the current post hoc analysis. Secondary efficacy measures included the change in MADRS individual items, MADRS response (defined as a decrease from baseline of $\geq 50 \%$ in MADRS total score) and remission (defined as MADRS total score of $\leq 12$ ) rates, HAM-D total scores and Hamilton Rating Scale for Anxiety (Hamilton 1959) (HAM-A) total scores at week 8. Additional post hoc efficacy endpoints were the evaluation of effect sizes and number-needed-to-treat (NNT). Data from analyses of patient-reported outcome measures of functioning and quality of life have been reported elsewhere (Gustafsson and Fajutrao 2011). Efficacy assessments were performed at baseline and weekly (BOLDER I and II) or every 2 weeks (EMBOLDEN I and II) until week 8 .

\section{Safety assessments}

Safety and tolerability assessments included the incidence and severity of adverse events and discontinuations because of adverse events, which were recorded at each visit. Adverse events were classified according to the Medical Dictionary for Regulatory Activities (MedDRA) terminology. Additional measures were the proportion of patients experiencing treatment-emergent mania/ hypomania (defined as a YMRS total score $\geq 16$ on two consecutive assessments or at final assessment, or an adverse event report of treatment-emergent mania or hypomania) and the incidence of adverse events potentially associated with extrapyramidal symptoms (EPS; including akathisia, cogwheel rigidity, dyskinesia, dystonia, extrapyramidal disorder, freezing phenomenon, hypertonia, muscle contractions involuntary, muscle rigidity, psychomotor hyperactivity, restlessness, tardive dyskinesia, and tremor). Other safety parameters comprised weight, clinical laboratory parameters using fasting and nonfasting samples, physical examination, and vital signs.

\section{Statistical analyses}

Data for patients with a diagnosis of bipolar II depression in the BOLDER I and II and EMBOLDEN I and II studies were pooled in order to enhance the precision of the statistical analyses. Efficacy analyses were conducted in the pooled intent-to-treat (ITT) population (patients who received at least one dose of study medication and had at least one post-baseline efficacy assessment) using last observation carried forward (LOCF) methodology. Changes from baseline in primary and secondary efficacy measures for quetiapine 300 or $600 \mathrm{mg} /$ day versus placebo were evaluated using analysis of covariance (ANCOVA) with baseline score as the covariate, treatment and bipolar diagnosis strata as fixed effects, and country (EMBOLDEN I and II) or center (BOLDER I and II) as a random effect. The relationship between severity (MADRS total score at baseline) and treatment response (MADRS total score at the end of treatment) was investigated in an exploratory analysis of the ITT population by plotting the individual data and superimposing linear regression lines based on an ANCOVA with baseline score as the covariate and treatment as a fixed effect. Probability levels $(p<0.05, p<0.01$, $p<0.001)$ are provided; however, these should be viewed 
with caution due to the post hoc nature of this analysis. It should also be noted that the probability levels were not adjusted for multiplicity.

Categorical changes, such as MADRS response and remission, were analyzed with the Cochran-MantelHaenszel test. Effect sizes, assessed using mixed-model repeated measures (MMRM) methodology based on observed cases data, were calculated as the improvement in quetiapine score versus placebo divided by the pooled standard deviation (SD). The NNT in order to achieve response was calculated according to the formula: $1 /$ (number of placebo responders - number of quetiapine responders); an equivalent formula calculated the NNT to achieve remission. An NNT of 1 would indicate that all patients in the quetiapine group were responders/ remitters compared with none of the patients in the placebo group. Analyses of safety variables were performed on the pooled safety population (i.e., patients who received at least one dose of the study medication) and were presented descriptively.

\section{Results}

Patient disposition is shown in Figure 1. A total of 776 (35.2\%) patients with bipolar II depression were included in the ITT population $(283,289$, and 204 patients received quetiapine $300 \mathrm{mg} /$ day, quetiapine $600 \mathrm{mg} /$ day, or placebo, respectively). The safety population comprised 819 patients with bipolar II depression (298, 307, and 214 patients received quetiapine $300 \mathrm{mg} /$ day, quetiapine $600 \mathrm{mg} /$ day, or placebo, respectively), representing 35.4\% of the total pooled safety population of patients with bipolar I or II depression from the four studies $(N=2,314)$.

At baseline, the demographic and clinical characteristics were similar among treatment groups (Table 1). The baseline symptom severity scores indicated a patient population with moderate to severe depression without mania symptoms.

\section{Primary efficacy outcome: Montgomery-Åsberg depression rating scale total score}

Among patients with bipolar II disorder, treatment with quetiapine resulted in significantly greater improvements in depression symptoms compared with placebo, as measured by mean change in MADRS total score from baseline to week 8 (mean [SE] -15.58 [0.62] and -14.88 [0.62] for quetiapine 300 and $600 \mathrm{mg} /$ day, respectively, vs-11.61 [0.70] for placebo; LOCF; $p<0.001$, both doses). Significant separation from placebo was observed from week 1 for both doses of quetiapine and was maintained through week 8 (Figure 2). Effect sizes, based on MADRS scores, were moderate for both quetiapine 300 and $600 \mathrm{mg} /$ day (MMRM: 0.44 and 0.47, respectively, $p<0.001$ vs placebo; Figure 3 ). The effect sizes in the bipolar I population in the four trials were 0.58 for quetiapine $300 \mathrm{mg} /$ day and 0.64 for quetiapine $600 \mathrm{mg} /$ day (Figure 3).

Patients with bipolar II disorder stratified by a rapid( $\geq 4$ mood episodes per year) or nonrapid-cycling course also demonstrated significant improvements in MADRS total score at week 8. Among patients without a rapidcycling course, MADRS total score improved significantly by a mean (SE) of $15.18(0.67)$ and $14.25(0.66)$ with quetiapine 300 and $600 \mathrm{mg} /$ day compared with $11.58(0.75)$ points for placebo $(p<0.001$ and $p=$ 0.005 for quetiapine 300 and $600 \mathrm{mg} /$ day, respectively) at week 8 . Significant symptomatic improvements at week 8 were also observed in patients with rapid cycling: 16.80 (1.63) and 16.92 (1.71) for quetiapine 300 and $600 \mathrm{mg} /$ day versus 11.12 (1.95) for placebo ( $p=0.011$ and $p=0.012$, respectively). In the exploratory analysis of the relationship between MADRS total score at baseline and end of treatment, there was an indication that the difference between placebo and both quetiapine doses at end of treatment increased as baseline score increased (Table 2; Figure 4). However, given the post hoc and exploratory nature of this analysis where the studies were not designed for this purpose, no formal inference can be made.

\section{Secondary efficacy outcomes MADRS item analyses}

Following 8 weeks of treatment, quetiapine at doses of 300 and $600 \mathrm{mg} /$ day was associated with significant improvements in the majority of the individual MADRS items when compared with placebo ( $p<0.05$ vs placebo, Figure 5), with the exceptions of apparent sadness for quetiapine $300 \mathrm{mg} /$ day, and concentration difficulties and lassitude for $600 \mathrm{mg} /$ day. From week 4 onward, there were significantly greater improvements in MADRS Item 10 (suicidal thoughts) scores with both doses of quetiapine $(p<0.05$ vs placebo).

\section{MADRS response and remission}

By week 8, significantly higher proportions of patients treated with quetiapine 300 and $600 \mathrm{mg} /$ day had achieved response and remission when compared with placebo. Among quetiapine-treated patients, 64.7\% (300 mg/day) and 62.6\% (600 mg/day) were classified as responders at week 8 compared with $49.0 \%$ of placebotreated patients $(p<0.001$ and $p<0.01$ for 300 and $600 \mathrm{mg} /$ day, respectively; ITT, LOCF). When compared with placebo $(46.1 \%)$, significantly more quetiapinetreated patients met remission criteria at week $8(65.0 \%$ and $61.9 \%$, respectively; $p<0.001$ vs placebo; ITT, LOCF). At week 8, NNT for response and remission were 6 and 5 for quetiapine $300 \mathrm{mg} /$ day and 7 and 6 for quetiapine $600 \mathrm{mg} /$ day, respectively. 


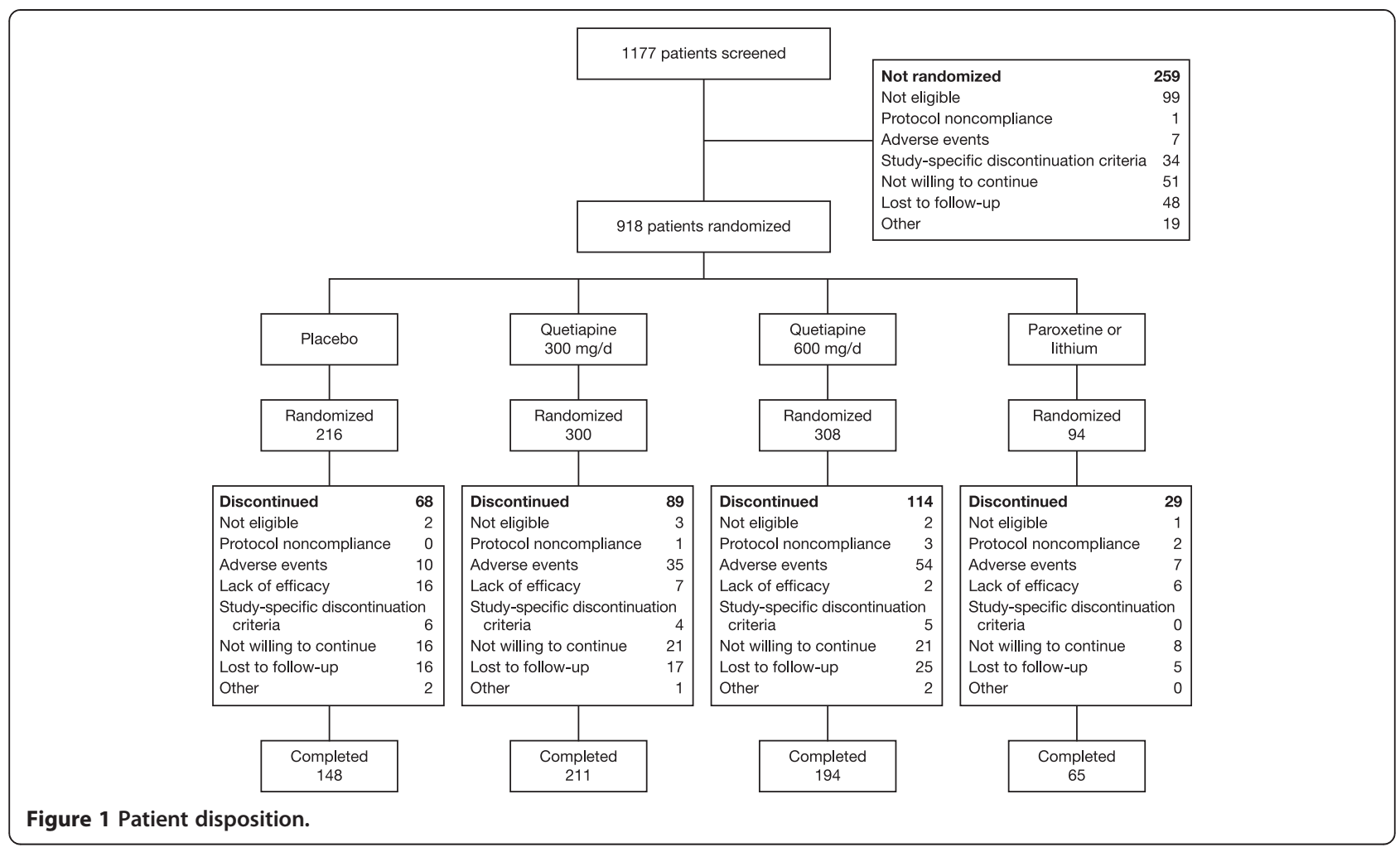

\section{Hamilton rating scale for depression total score}

Patients who were treated with quetiapine 300 and $600 \mathrm{mg} /$ day demonstrated significantly greater improvements in HAM-D total score from week 1 through week 8 compared with placebo $(p<0.001$; ITT, LOCF). At week 8 , HAM-D total scores improved by a mean (SE) of $14.00(0.49)$ and $13.57(0.49)$ points for quetiapine 300 and $600 \mathrm{mg} /$ day, respectively, versus 10.88 (0.55) for placebo $(p<0.001)$.

Table 1 Baseline demographic and clinical characteristics (safety population)

\begin{tabular}{llll}
\hline & $\begin{array}{l}\text { Quetiapine } \\
\mathbf{3 0 0} \mathbf{~ m g / d a y} \\
(\boldsymbol{n}=\mathbf{2 9 8})\end{array}$ & $\begin{array}{l}\text { Quetiapine } \\
\mathbf{6 0 0} \mathbf{~ m g / d a y} \\
(\boldsymbol{n}=\mathbf{3 0 7})\end{array}$ & $\begin{array}{l}\text { Placebo } \\
(\boldsymbol{n}=\mathbf{2 1 4})\end{array}$ \\
\hline $\begin{array}{llll}\text { Gender,\% } \\
\text { Male }\end{array}$ & 36.9 & 39.7 & 37.4 \\
$\quad$ Female & 63.1 & 60.3 & 62.6 \\
Age, mean (years) & 38.4 & 39.4 & 37.7 \\
Weight, mean (kg) & 79.7 & 80.1 & 78.9 \\
BMI, mean & 28.0 & 28.0 & 27.8 \\
Symptom rating, & & & \\
mean total score & & 27.5 & 28.0 \\
MADRS & 27.8 & 24.0 & 24.2 \\
HAM-D & 24.2 & 4.5 & 5.0 \\
YMRS & 4.5 & 18.6 & 19.1 \\
\hline HAM-A & 19.2 & &
\end{tabular}

\section{Hamilton rating scale for anxiety total score}

Following quetiapine treatment, patients demonstrated significant improvements in symptoms of anxiety, as measured by mean change from baseline in HAM-A total score at week 8 ( $p<0.05$ both doses vs placebo; Figure 6). Significant improvements in HAM-A total score with quetiapine 300 and $600 \mathrm{mg} /$ day versus placebo were observed from week 1 onward $(-9.62[p<0.001]$ and -8.89 $[p<0.05]$ vs -7.34 at week 8 , respectively; ITT, LOCF).

\section{Safety}

Overall rates of adverse events in the pooled safety population were $73.8 \%, 74.3 \%$, and $67.8 \%$ for the quetiapine $300 \mathrm{mg} /$ day, $600 \mathrm{mg} /$ day, and placebo arms, respectively. As shown in Table 3, common adverse events associated with quetiapine 300 and $600 \mathrm{mg} /$ day included dry mouth, somnolence, sedation, and dizziness. Adverse events potentially related to extrapyramidal symptoms were observed in $12.4 \%, 8.8 \%$, and $6.1 \%$ of the quetiapine $300 \mathrm{mg} /$ day, quetiapine $600 \mathrm{mg} /$ day, and placebo groups, respectively. Rates of treatmentemergent mania/hypomania during acute treatment were similar among the treatment groups: $1.3 \%, 3.3 \%$, and $2.3 \%$ for quetiapine $300 \mathrm{mg} /$ day, $600 \mathrm{mg} /$ day, and placebo arms, respectively. Rates of discontinuation because of adverse events were $12.1 \%$ for quetiapine $300 \mathrm{mg} /$ day, $17.9 \%$ for quetiapine $600 \mathrm{mg} /$ day, and 5.1\% for placebo. Changes from baseline in weight and 


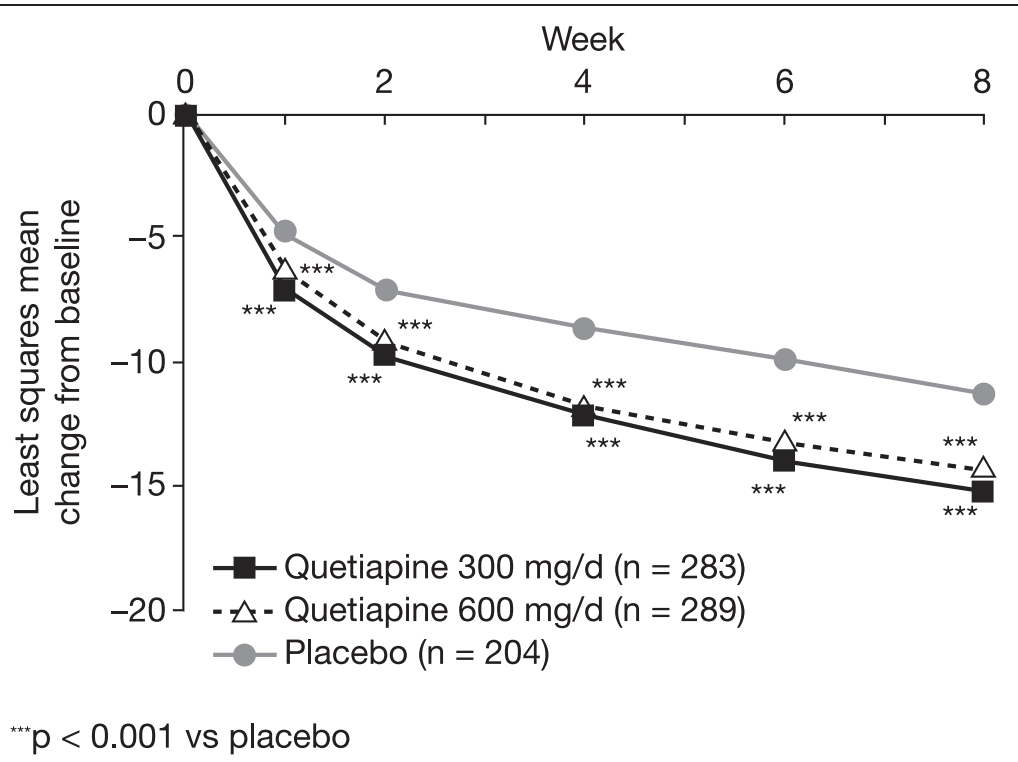

Figure 2 Mean change from baseline to week 8 in MADRS total score (ITT population; LOCF).

laboratory parameters during acute treatment are presented in Table 4. Although average weight gain was only about $1 \mathrm{~kg}$ greater in the two groups receiving quetiapine, the proportions of patients in both arms gaining at least $7 \%$ body weight was higher in both quetiapine arms (Table 4).

\section{Discussion}

To our knowledge this pooled post hoc analysis of patients with bipolar II disorder experiencing an acute episode of depression represents the largest population available for evaluation to date. Quetiapine monotherapy at doses of 300 and $600 \mathrm{mg} /$ day was significantly more effective than placebo at reducing the symptoms of depression as assessed by the change in MADRS total score. The improvements during quetiapine treatment were observed at week 1 and were sustained up to week 8. Significant improvements in 9 and 8 of the 10 MADRS individual items were apparent with quetiapine 300 and $600 \mathrm{mg} /$ day, respectively, indicating the efficacy

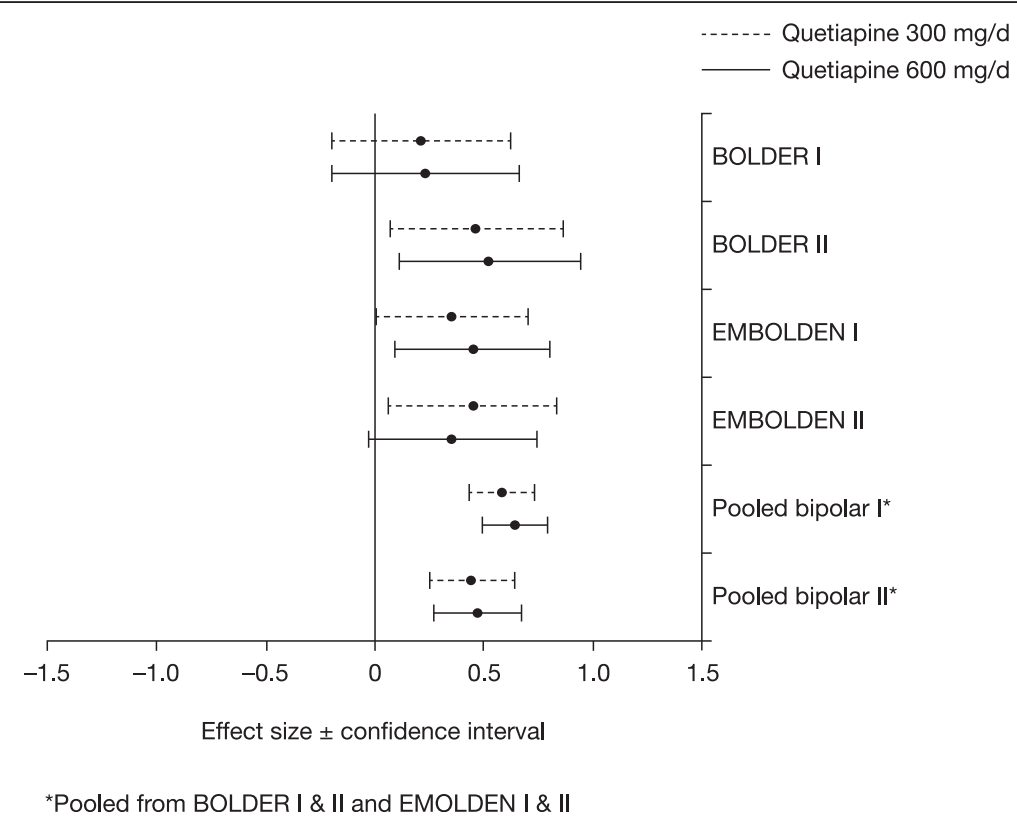

Figure 3 Effect sizes of quetiapine 300 and $600 \mathrm{mg} /$ day in patients with bipolar I or bipolar II disorder. 
Table 2 Relationship between MADRS total score at baseline and of treatment (ITT) (ANCOVA with baseline score as covariate and treatment as fixed effect)

\begin{tabular}{|c|c|c|c|c|c|c|}
\hline Treatment & Dependent variable & Fixed factor & Estimate & Degrees of freedom & $t$ value & $p$ value \\
\hline \multirow[t]{2}{*}{ Quetiapine 300 mg/day } & MADRS at end of treatment & Intercept & -0.242 & 281 & -0.11 & 0.9119 \\
\hline & & MADRS at baseline & 0.445 & 281 & 5.86 & $<0.0001$ \\
\hline \multirow[t]{2}{*}{ Quetiapine 600 mg/day } & MADRS at end of treatment & Intercept & 1.127 & 287 & 0.53 & 0.5998 \\
\hline & & MADRS at baseline & 0.423 & 287 & 5.59 & $<0.0001$ \\
\hline \multirow[t]{2}{*}{ Placebo } & MADRS at end of treatment & Intercept & -4.302 & 202 & -1.26 & 0.2086 \\
\hline & & MADRS at baseline & 0.741 & 202 & 6.23 & $<0.0001$ \\
\hline
\end{tabular}

of quetiapine over a broad range of depressive symptoms. An exploratory analysis indicated that the difference between placebo and both doses of quetiapine at the end of treatment increased with initial severity (i.e., baseline MADRS total score). Across all analyses, the lower dose was as effective as the higher dose in patients with bipolar II disorder and tended to be associated with lower reports of adverse events.

The findings of this pooled analysis are fully consistent with those of the individual trials in which both doses of quetiapine were associated with statistically or numerically greater improvements in MADRS total score compared with placebo in the bipolar II subgroups. In the EMBOLDEN II and BOLDER II trials, quetiapine 300 and $600 \mathrm{mg} /$ day resulted in significant improvements in MADRS total score from week 1 or 2 through to week 8, whereas in the EMBOLDEN I and BOLDER I trials there were no significant differences between either quetiapine dose and placebo at week 8 although there were significant differences from placebo at earlier assessments. This latter result may be explained by the relatively low power of the subanalyses in each of the trials, where the predominant number of patients had bipolar I rather than bipolar II depression.

Although these studies observed a relatively high placebo remission rate $(46.1 \%)$, the remission rate for each dose of quetiapine $(65.0 \%$ and $61.9 \%$ for quetiapine 300 and $600 \mathrm{mg} /$ day, respectively) was nevertheless significantly higher and indicated that the benefit of active quetiapine was clinically significant. The effect sizes in the bipolar II population of the four quetiapine trials were moderate for both quetiapine 300 and $600 \mathrm{mg} /$ day (0.44 and 0.47 , respectively). In comparison, the effect sizes in the bipolar I population were also moderate but numerically higher (0.58 for quetiapine $300 \mathrm{mg} /$ day and 0.64 for quetiapine $600 \mathrm{mg} /$ day). A high placebo response rate has also been observed in other trials of agents evaluated in bipolar depression (Calabrese et al. 2008; Thase et al. 2008). Confirming the antidepressant efficacy observed on the MADRS scale, both doses of

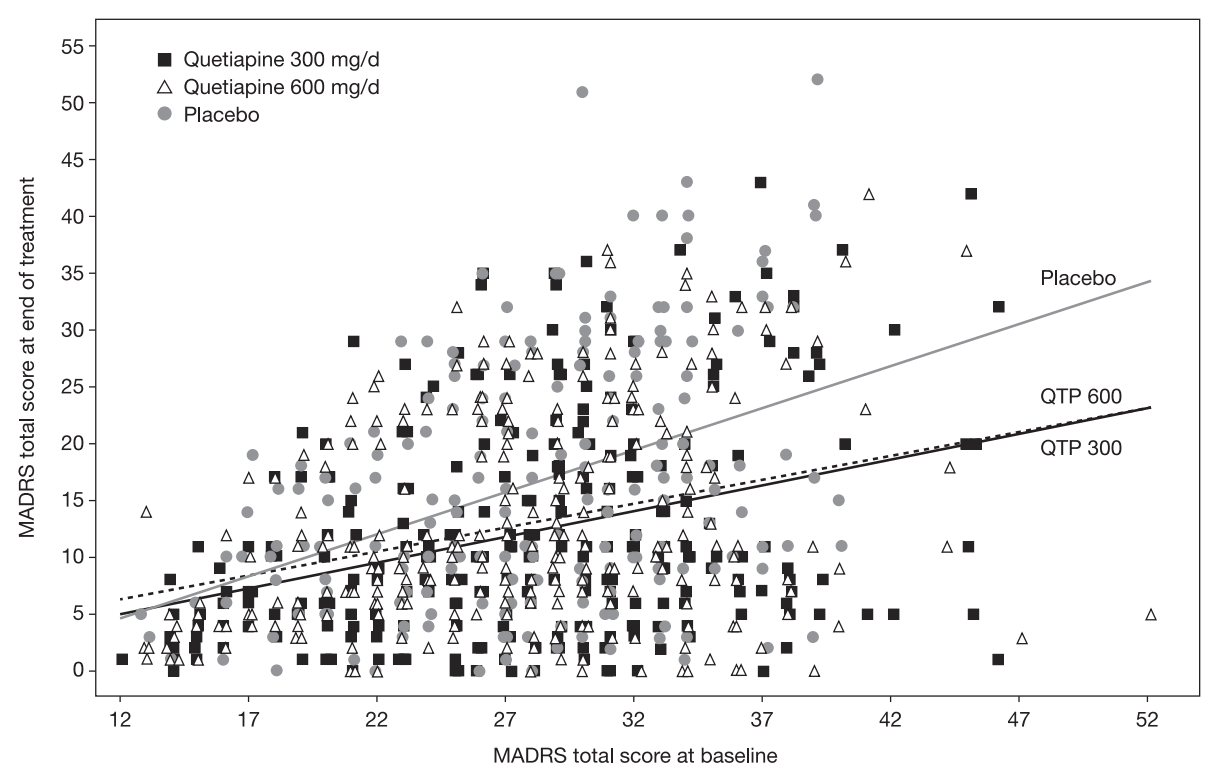

Figure 4 Relationship between MADRS total score at baseline and of treatment (ITT). 


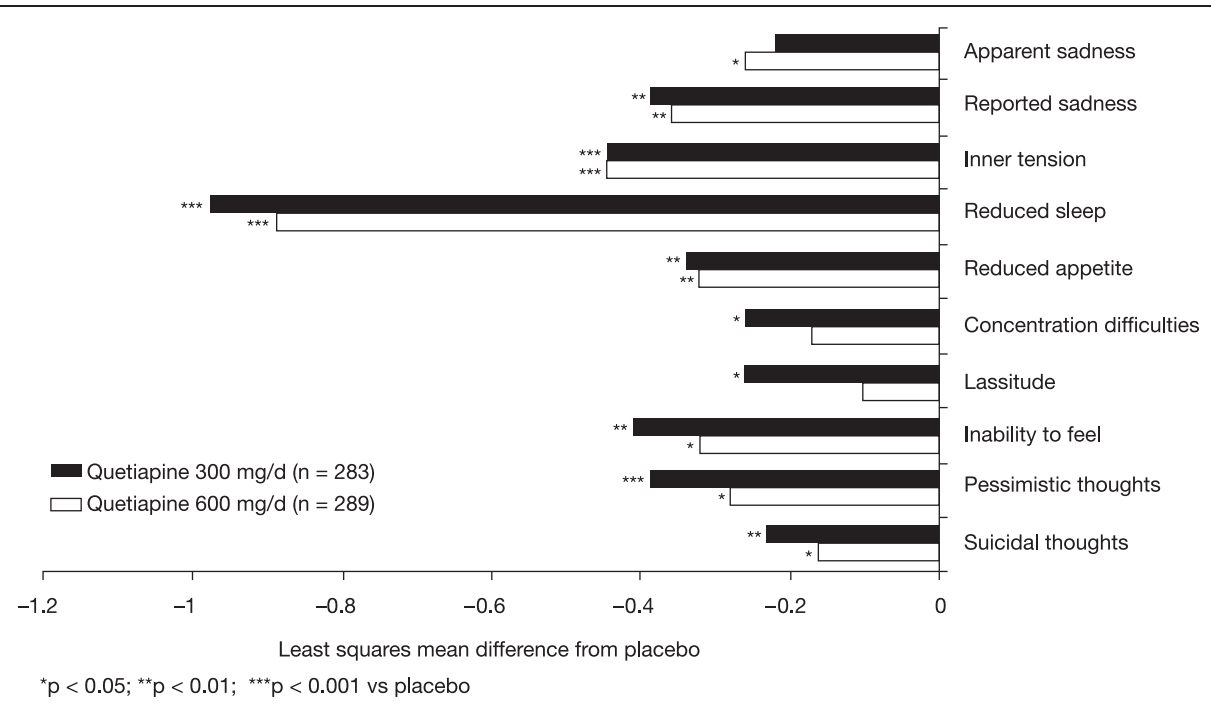

Figure 5 Difference in mean change from baseline in MADRS individual item scores at week 8 (ITT population; LOCF).

quetiapine were associated with significantly greater improvements in HAM-D total score from week 1 through week 8 .

The broad therapeutic profile of quetiapine is demonstrated by the symptomatic improvements in patients with rapid cycling, who typically represent a management challenge (Bauer et al. 2008; Kupka et al. 2005; Lee et al. 2010), and may be particularly common in bipolar II (Berk and Dodd 2004; Kupka et al. 2003). A planned subanalysis of the BOLDER I study indicated that quetiapine was as effective in bipolar I or II patients with a history of rapid cycling as it was in patients with nonrapid cycling (Vieta et al. 2007). The current pooled analysis extends these observations by demonstrating significant decreases in MADRS total score at week 8 with both quetiapine doses both in patients with bipolar II depression who have rapid cycling and in those with less frequent episodes.

Comorbid anxiety is common among bipolar II patients and can have a large, adverse impact on treatment response, functioning, and quality of life (Angst et al. 2011; Gao et al. 2008; Judd et al. 2003; Otto et al. 2006). In the combined BOLDER I and II trials, quetiapine was effective in the treatment of bipolar I and II depression regardless of the severity of baseline anxiety (Lydiard et al. 2009). Patients with bipolar II depression in the

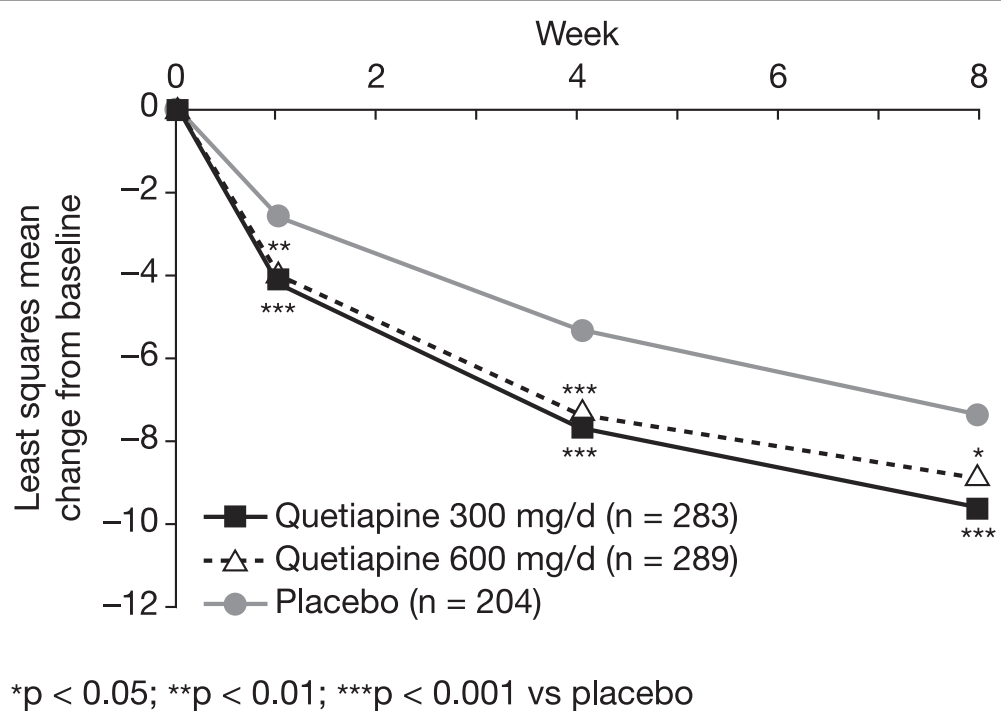

Figure 6 Mean change from baseline to week 8 in HAM-A total score (ITT population; LOCF). 
Table 3 Common adverse events ( $\geq 5 \%$ of patients in any group; safety population)

\begin{tabular}{lccc}
\hline $\begin{array}{l}\text { Adverse } \\
\text { event, } \boldsymbol{N} \text { (\%) }\end{array}$ & $\begin{array}{c}\text { Quetiapine } \\
\mathbf{3 0 0} \mathbf{~ m g / d a y} \\
(\boldsymbol{n}=\mathbf{2 9 8})\end{array}$ & $\begin{array}{c}\text { Quetiapine } \\
\mathbf{6 0 0} \mathbf{~ m g / d a y} \\
(\boldsymbol{n}=\mathbf{3 0 7})\end{array}$ & $\begin{array}{c}\text { Placebo } \\
(\boldsymbol{n}=\mathbf{2 1 4})\end{array}$ \\
\hline Dry mouth & $94(31.5)$ & $90(29.3)$ & $21(9.8)$ \\
Somnolence & $65(21.8)$ & $60(19.5)$ & $18(8.4)$ \\
Sedation & $60(20.1)$ & $59(19.2)$ & $12(5.6)$ \\
Dizziness & $39(13.1)$ & $48(15.6)$ & $12(5.6)$ \\
Headache & $27(9.1)$ & $37(12.1)$ & $40(18.7)$ \\
Fatigue & $26(8.7)$ & $30(9.8)$ & $14(6.5)$ \\
Constipation & $24(8.1)$ & $24(7.8)$ & $9(4.2)$ \\
Nausea & $23(7.7)$ & $22(7.2)$ & $21(9.8)$ \\
Diarrhea & $12(4.0)$ & $8(2.6)$ & $17(7.9)$ \\
Insomnia & $8(2.7)$ & $2(0.7)$ & $14(6.5)$ \\
Upper respiratory tract infection & $7(2.3)$ & $7(2.3)$ & $11(5.1)$ \\
\hline
\end{tabular}

BOLDER I trial did not show a statistically significant difference in HAM-A total score from placebo (Hirschfeld et al. 2006), which again may have been due to the smaller number of patients available for analysis. Quetiapine treatment resulted in significant improvements in the symptoms of anxiety in the current analysis among this larger population with bipolar II depression, the majority of whom had mild-to-moderate anxiety at baseline.

The reductions in symptom severity during quetiapine treatment in patients with bipolar II depression are accompanied by improvements in patient-reported outcomes. Pooled findings from the BOLDER and EMBOLDEN trials showed clear improvements with both doses of quetiapine in overall functioning, individual domains of social and occupational functioning, as well as quality of life (Gustafsson and Fajutrao 2011). These results are particularly promising given

\begin{tabular}{|c|c|c|c|}
\hline $\begin{array}{l}\text { Mean change from } \\
\text { randomization (SD) }\end{array}$ & $\begin{array}{c}\text { Quetiapine } \\
300 \mathrm{mg} / \text { day } \\
(n=298)\end{array}$ & $\begin{array}{c}\text { Quetiapine } \\
600 \mathrm{mg} / \mathrm{day} \\
(n=307)\end{array}$ & $\begin{array}{l}\text { Placebo } \\
(n=214)\end{array}$ \\
\hline Total cholesterol (mg/dL) & $-2.3(2.1)$ & $0.8(2.0)$ & $-3.5(2.5)$ \\
\hline LDL cholesterol (mg/dL) & $-5.3(1.7)$ & $-0.3(1.7)$ & $-4.4(1.9)$ \\
\hline HDL cholesterol (mg/dL) & $-0.5(0.6)$ & $-1.6(0.6)$ & $-1.0(0.7)$ \\
\hline Triglycerides (mg/dL) & $21.4(5.9)$ & $14.2(4.9)$ & $9.0(7.4)$ \\
\hline Glucose (mg/dL) & $3.3(1.0)$ & $2.8(0.9)$ & $1.8(1.1)$ \\
\hline Insulin (pmol/L) & $31.0(8.4)$ & $24.2(6.1)$ & $12.5(8.5)$ \\
\hline Mean weight change, kg (SE) & $1.0(0.19)$ & $1.1(0.23)$ & $0.0(0.17)$ \\
\hline Weight change $\geq 7 \%, n(\%)$ & $17(6.5)$ & $24(9.7)$ & $4(2.2)$ \\
\hline
\end{tabular}

${ }^{a}$ Mean change from randomization to continuation phase to the end of treatment. that a diagnosis of bipolar II disorder is associated with poor health-related quality of life even during periods of euthymia (Maina et al. 2007).

Quetiapine was tested in the four EMBOLDEN and BOLDER studies under rigorous conditions. The only other agent that has been tested under similarly robust circumstances in bipolar II depression is lamotrigine, and the data are inconsistent among studies (Swartz and Thase 2011). Among other treatments tested in bipolar II depression, the data for lithium, antidepressants (selective serotonin re-uptake inhibitors), $\mathrm{N}$-acetyl cysteine, and pramipexole are suggestive of efficacy but not conclusive (Magalhaes et al. 2011; Swartz and Thase 2011). Further studies are required to establish the relative therapeutic position of these agents in the bipolar II disorder treatment armamentarium, with long-term trials being essential.

One implication of demonstrating that a medication has efficacy as an acute phase therapy is the need to document longer-term benefit for relapse prevention. The continuation phase of the EMBOLDEN studies included 231 patients with bipolar II depression who received quetiapine for 26 to 52 weeks and is one of the largest bipolar II patient populations studied in a continuation phase trial (Young et al. 2012). Quetiapine was associated with a reduced risk of any mood event or depressive relapse compared with placebo (Young et al. 2012), suggesting that it is an efficacious treatment in both the short and long term in patients with bipolar II depression.

The safety and tolerability profile of quetiapine is well established in clinical trials. In this analysis of patients with bipolar II depression, safety results during acute treatment with quetiapine were in line with observations in the individual BOLDER and EMBOLDEN patient populations (Calabrese et al. 2005; McElroy et al. 2010; Thase et al. 2006; Young et al. 2010). The adverse event profile in this patient population was qualitatively similar to findings in acute and maintenance studies of quetiapine monotherapy in patients with bipolar I or II disorder (Bowden et al. 2005; McIntyre et al. 2005; Weisler et al. 2011). However, patients with bipolar II disorder are thought to be more sensitive to side effects than bipolar I disorder patients. In the combined BOLDER I and II trials, the rate of discontinuation from quetiapine due to any adverse event was slightly higher among bipolar II disorder patients than for those with bipolar I disorder (Suppes et al. 2008).

Overall, there were changes in some glucose and lipid parameters and increases in weight with quetiapine, which were consistent with previous observations (Calabrese et al. 2005; McElroy et al. 2010; Thase et al. 2006; Young et al. 2010). The prescribing information for quetiapine recommends appropriate clinical monitoring for alterations in 
lipids, including blood lipid testing at the beginning of and periodically during treatment (Seroquel Prescribing Information 2012). Moreover, any patient treated with second-generation antipsychotics should be monitored for symptoms of hyperglycemia including polydipsia, polyuria, polyphagia, and weakness (Seroquel Prescribing Information 2012). When starting treatment, patients with diabetes or risk factors for diabetes should undergo blood glucose testing before and during treatment (Seroquel Prescribing Information 2012).

Treatment-emergent mania is a concern during treatment of bipolar depression with conventional antidepressants, although the extent to which it occurs in bipolar II depression remains a matter of debate (Altshuler et al. 2006; Leverich et al. 2006; Vazquez et al. 2011). In the current analyses, the rates of treatment-emergent hypomania/mania were similar for the two quetiapine doses and for placebo, indicating that quetiapine poses a minimal risk for affective switching in patients with bipolar II depression. However, the incidence of treatment-emergent mania/ hypomania may have been underestimated using the definition employed in the trials (i.e., a YMRS total score $\geq 16$ on two consecutive assessments or at final assessment or an adverse event of mania/hypomania) as patients with bipolar II disorder who exhibit frank mania may only do so briefly; moreover, patients who have a YMRS total score $\geq 16$ on two consecutive assessments may have bipolar I disorder.

There are a number of potential limitations to this pooled analysis. An important consideration is its post hoc nature. Furthermore, the generalizability of the findings should be considered in the context of the inclusion and exclusion criteria of the BOLDER and EMBOLDEN trials. The patients in these studies had few significant co-morbidities and were likely to have a low risk of suicide, although this may not be the case in all patients with bipolar disorder (Perugi et al. 2013). The analysis was based on 8-week studies and gives an insight into the short-term safety and tolerability of quetiapine in this population. Longer-term information is provided by the continuation phase of the EMBOLDEN studies, which included patients with bipolar II depression who received quetiapine for up to 52 weeks (Young et al. 2012).

\section{Conclusions}

These analyses on the largest sample of patients with bipolar II depression studied to date support the efficacy and tolerability of quetiapine 300 and $600 \mathrm{mg} /$ day in treating bipolar II depression.

\footnotetext{
Abbreviations

ANCOVA: Analysis of covariance; BOLDER: BipOLarDepRession; DSMIV: Diagnostic and statistical manual of mental disorders, fourth edition; EMBOLDEN: Efficacy of monotherapy seroquel in BipOLarDepressioN;
}

EPS: Extrapyramidal symptoms; HAM-A: Hamilton rating scale for anxiety; HAM-D: Hamilton rating scale for depression; ITT: Intent-to-treat; LOCF: Last observation carried forward; MADRS: Montgomery-Åsberg depression rating scale; MedDRA: Medical dictionary for regulatory activities; MMRM: Mixedeffect model repeated measure; NNT: Numbers needed to treat; YMRS: Young mania rating scale.

\section{Competing interests}

Michael Berk has received grant/research support from NIH, NHMRC, Simons Autism Foundation, Stanley Medical Research Foundation, MBF, Beyond Blue, Geelong Medical Research Foundation, Bristol-Myers Squibb, Eli Lilly, Glaxo SmithKline, Organon, Novartis, MaynePharma, and Servier. He was a speaker at AstraZeneca, Bristol-Myers Squibb, Eli Lilly, Glaxo SmithKline, Janssen Cilag, Lundbeck, Pfizer, SanofiSynthelabo, Servier, Solvay, and Wyeth. Also, he was a consultant at AstraZeneca, Bristol-Myers Squibb, Eli Lilly, Glaxo SmithKline, Janssen Cilag, Lundbeck, and Servier.

Allan $\mathrm{H}$ Young was employed by Imperial College London. He is an Honorary Consultant WLMHT (NHS). He was paid for lectures and advisory boards for all major pharmaceutical companies with drugs used in affective and related disorders. He has no share holdings in pharmaceutical companies. He is a Lead Investigator for EMBOLDEN Study (AstraZeneca), BCl Neuroplasticity study, and Aripiprazole Mania Study. Also, he is an investigator which initiated studies from AZ, Eli Lilly, Wyeth. In addition, he received grant funding (past and present) from NIMH (USA), CIHR (Canada), NARSAD (USA), Stanley Medical Research Institute (USA), MRC (UK), Wellcome Trust (UK), Royal College of Physicians (Edin), BMA (UK), UBC-VGH Foundation (Canada), WEDC (Canada), CCS Depression Research Fund (Canada), and MSFHR (Canada). He is a co-holder of one European patent for the use of glucocorticoid antagonists in the treatment of depression.

Trisha Suppes, for the period 2008-2011, has received research funding or medication support from Abbott Laboratories, AstraZeneca, JDS

Pharmaceuticals, NIMH, Pfizer, the Stanley Medical Research Institute, and Sunovion Pharmaceuticals. She has served in a consulting or advisory capacity to Orexigen Therapeutics and has received royalties or honorarium from Medscape, CNS Drug Supplement, and Jones and Bartlett (formerly Compact Clinicals).

Joseph Calabrese has received federal funding from the Department of Defense, Health Resources Services Administration and National Institute of Mental Health. He has received research support from Abbott, AstraZeneca, Bristol-Myers Squibb, Cephalon, Cleveland Foundation, Eli Lilly,

GlaxoSmithKline, Janssen, NARSAD, Repligen, Stanley Medical Research Institute, Takeda, and Wyeth. He consulted to or served on advisory boards of Abbott, AstraZeneca, Bristol-Myers Squibb, Cephalon, Dainippon Sumitomo, Elan, EPI-Q, Inc., Forest, France Foundation, GlaxoSmithKline, Janssen, Johnson and Johnson, Lundbeck, Merck, Neurosearch, Ortho-McNeil, Otsuka, Pfizer, Repligen, Schering-Plough, Servier, Solvay, Supernus, Synosia, Takeda, Teva, and Wyeth. He has provided CME lectures supported by Abbott, AstraZeneca, Bristol-Myers Squibb, France Foundation,

GlaxoSmithKline, Janssen, Johnson and Johnson, Lundbeck, Sanofi Aventis, Schering-Plough, Pfizer, Solvay, and Wyeth.

Susan L McElroy has served as a consultant to or on the advisory boards of Alkermes, AstraZeneca, Bracket, Corcept, Eli Lilly, Jazz Pharmaceuticals, MedAvante, Pfizer, Shire, and Teva. She has been a principal or coinvestigator on research studies sponsored by Abbott Laboratories, Agency for Healthcare Research and Quality, Alkermes, AstraZeneca, Bristol-Myers Squibb, Eli Lilly, Forrest Laboratories, GlaxoSmithKline, Jazz Pharmaceuticals, Marriott Foundation, National Institute of Mental Health (NIMH), Orexigen Therapeutics, Schering-Plough, Shire, Takeda, and Transcept. She is also inventor on United States Patent No. 6,323,236 B2, Use of Sulfamate Derivatives for Treating Impulse Control Disorders, and, along with the patient's assignee, University of Cincinnati, Cincinnati, $\mathrm{OH}$, has received payment from Johnson \& Johnson Pharmaceutical Research \& Development, L.L.C., which has exclusive rights under the patent. Filed February 18, 2000; approved November 27, 2001.

Michael $E$ Thase has served as a consultant to or on the advisory boards of AstraZeneca, Bristol-Myers Squibb, DeyPharma, Eli Lilly, Forest, Gerson Lehman Group, GlaxoSmithKline, Guidepoint Global, H. Lundbeck A/S, MedAvante, Merck (including Organon and Schering-Plough), Neuronetics, Novartis, Otsuka, Ortho-McNeil (including Johnson \& Johnson), Pamlab, Pfizer (including Wyeth), Shire, Supernus, Takeda, and Transcept. He has received grant/research support from Agency for Healthcare Research and Quality, Eli 
Lilly, Forest Laboratories, GlaxoSmithKline, National Institute of Mental Health, Otsuka, and Sepracor. Prior to 2011, he served on the speakers bureaus of AstraZeneca, Bristol-Myers Squibb, Eli Lilly, Merck, and Pfizer. Dr. Thase has equity holdings in MedAvante and receives royalty income from American Psychiatric Publishing, Guilford Publications, Herald House, and W.W. Norton. Dr Thase's wife is employed by Embryon (formerly Advogent). Urban Gustafsson is a former employee of AstraZeneca. Willie Earley is a former employee of AstraZeneca Pharmaceuticals LP.

\section{Authors' contributions}

AY, JC, SM, TS, and MT made substantial contributions to the acquisition of data and interpretation of data; $\mathrm{UG}, \mathrm{MB}$, and WE contributed to the analysis and interpretation of data. UG provided statistical analysis. All authors were involved in drafting the manuscript or revising it critically for important intellectual content. All authors read and approved the final manuscript.

\section{Acknowledgments}

We thank AnushaBolonna, PhD, and Chris Langford, PhD, from PAREXEL MMS, who provided medical writing support funded by AstraZeneca. The studies were funded by AstraZeneca.

\section{Author details}

'Department of Psychiatry, Imperial College, London SW7 2AZ, UK. ¿University Hospitals Case Medical Center, Case Western Reserve University, Cleveland, OH 44106, USA. ${ }^{3}$ Formerly AstraZeneca R\&D, Södertälje 151 85, Sweden. ${ }^{4}$ School of Medicine, Deakin University, Deakin 3217, Australia. ${ }^{5}$ Lindner Center of HOPE, Mason, OH 45040, USA. ${ }^{6}$ University of Cincinnati College of Medicine, Cincinnati, OH 45229, USA. 'Department of Psychiatry, University of Pennsylvania School of Medicine, Western Pennsylvania, PA 19104, USA. ${ }^{8}$ Department of Psychiatry and Behavioral Sciences, Stanford Medical Center and VA Palo Alto Health Care System, Palo Alto, CA 94304, USA. ${ }^{9}$ Formerly AstraZeneca Pharmaceuticals LP, Wilmington, DE 19803, USA. ${ }^{10}$ Orygen Youth Health Research Centre, Centre for Youth Mental Health, Parkville, VIC 3052, Australia. ${ }^{11}$ The Mental Health Research Institute of Victoria, Parkville, VIC 3052, Australia. ${ }^{12}$ Department of Psychiatry, Melbourne University, Parkville, VIC 3052, Australia. ${ }^{13}$ Centre for Affective Disorders, Institute of Psychiatry, King's College, London WC2R 2LS, UK.

Received: 3 April 2013 Accepted: 19 June 2013

Published: 4 July 2013

\section{References}

Altshuler LL, Suppes T, Black DO, Nolen WA, Leverich G, Keck PE Jr, Frye MA, Kupka R, McElroy SL, Grunze H, Kitchen CM, Post R. Lower switch rate in depressed patients with bipolar II than bipolar I disorder treated adjunctively with second-generation antidepressants. Am J Psychiatry. 2006; 163(2):313-5.

American Psychiatric Association. Diagnostic and Statistical Manual of Mental Disorders, Fourth Edition, Text Revision. 4th ed. Washington, DC: American Psychiatric Association; 2000

American Psychiatric Association. Practice guideline for the treatment of patients with bipolar disorder (revision). Am J Psychiatry. 2002; 159 Suppl 4: 1-50.

Angst J, Cui L, Swendsen J, Rothen S, Cravchik A, Kessler RC, Merikangas KR. Major depressive disorder with subthreshold bipolarity in the National Comorbidity Survey Replication. Am J Psychiatry. 2010; 167(10):1194-201.

Angst J, Gamma A, Azorin JM, Bowden CL, Perugi G, Vieta E, Young AH. Evidence-based efforts to re-define bipolar disorders. Bipolar Disord. 2011; 13 Suppl 1: 14.

Angst J, Gamma A, Bowden CL, Azorin JM, Perugi G, Vieta E, Young AH. Diagnostic criteria for bipolarity based on an international sample of 5,635 patients with DSM-IV major depressive episodes. Eur Arch Psychiatry Clin Neurosci. 2012; 262(1):3-11.

Bauer M, Beaulieu S, Dunner DL, Lafer B, Kupka R. Rapid cycling bipolar disorder-diagnostic concepts. Bipolar Disord. 2008; 10(1 Pt 2):153-62.

Benazzi F. Bipolar II, disorder: epidemiology, diagnosis and management. CNS Drugs. 2007; 21(9):727-40.

Berk M, Dodd S. Review: rapid cycling bipolar disorder associated with female gender and bipolar type II subgroup. Evid Based Ment Health. 2004; 7(3):91.

Berk M, Dodd S, Callaly P, Berk L, Fitzgerald P, de Castella AR, Filia S, Filia K, Tahtalian S, Biffin F, Kelin K, Smith M, Montgomery W, Kulkarni J. History of illness prior to a diagnosis of bipolar disorder or schizoaffective disorder. $J$ Affect Disord. 2007; 103(1-3):181-6.

Bowden CL, Grunze H, Mullen J, Brecher M, Paulsson B, Jones M, Vagero M, Svensson K. A randomized, double-blind, placebo-controlled efficacy and safety study of quetiapine or lithium as monotherapy for mania in bipolar disorder. J Clin Psychiatry. 2005; 66(1):111-21.

Calabrese JR, Keck PE Jr, Macfadden W, Minkwitz M, Ketter TA, Weisler RH, Cutler AJ, McCoy R, Wilson E, Mullen J. A randomized, double-blind, placebocontrolled trial of quetiapine in the treatment of bipolar I or II depression. Am J Psychiatry. 2005; 162(7):1351-60.

Calabrese JR, Huffman RF, White RL, Edwards S, Thompson TR, Ascher JA, Monaghan ET, Leadbetter RA. Lamotrigine in the acute treatment of bipolar depression: results of five double-blind, placebo-controlled clinical trials. Bipolar Disord. 2008; 10(2):323-33.

Cruz N, Sanchez-Moreno J, Torres F, Goikolea JM, Valenti M, Vieta E. Efficacy of modern antipsychotics in placebo-controlled trials in bipolar depression: a meta-analysis. Int J Neuropsychopharmacol. 2010; 13(1):5-14.

Fiedorowicz JG, Endicott J, Leon AC, Solomon DA, Keller MB, Coryell WH. Subthreshold hypomanic symptoms in progression from unipolar major depression to bipolar disorder. Am J Psychiatry. 2011; 168(1):40-8.

Gao K, Tolliver BK, Kemp DE, Verduin ML, Ganocy SJ, Bilali S, Brady KT, Shim SS, Findling RL, Calabrese JR. Differential interactions between comorbid anxiety disorders and substance use disorder in rapid cycling bipolar I or II disorder. J Affect Disord. 2008; 110(1-2):167-73.

Goodwin GM. Evidence-based guidelines for treating bipolar disorder: recommendations from the British Association for Psychopharmacology. J Psychopharmacol. 2003; 17(2):149-73.

Goodwin GM. Evidence-based guidelines for treating bipolar disorder: revised second edition-recommendations from the British Association for Psychopharmacology. J Psychopharmacol. 2009; 23(4):346-88.

Grunze H, Vieta E, Goodwin GM, Bowden C, Licht RW, Moller HJ, Kasper S. The World Federation of Societies of Biological Psychiatry (WFSBP) guidelines for the biological treatment of bipolar disorders: update 2010 on the treatment of acute bipolar depression. World I Biol Psychiatry. 2010; 11(2):81-109.

Gustafsson U, Fajutrao L. Effect of quetiapine on functioning and quality of life in bipolar depression [abstract]. Eur Psychiatry. 2011; 26(Suppl 1):1935.

Hamilton M. The assessment of anxiety states by rating. Br J Med Psychol. 1959; 32(1):50-5.

Hamilton M. A rating scale for depression. J Neurol Neurosurg Psychiatry. 1960; 23:56-62.

Hirschfeld RM, Weisler RH, Raines SR, Macfadden W. Quetiapine in the treatment of anxiety in patients with bipolar I or II depression: a secondary analysis from a randomized, double-blind, placebo-controlled study. J Clin Psychiatry. 2006; 67(3):355-62

Judd LL, Akiskal HS, Schettler PJ, Coryell W, Endicott J, Maser JD, Solomon DA, Leon AC, Keller MB. A prospective investigation of the natural history of the long-term weekly symptomatic status of bipolar II disorder. Arch Gen Psychiatry. 2003; 60(3):261-9.

Keck PE, Perlis RH, Otto MW, Carpenter D, Ross R, Docherty JP. The expert consensus guideline series: treatment of bipolar disorder. Postgraduate Med Special Report. 2004; 2004:1-120.

Kupka RW, Luckenbaugh DA, Post RM, Leverich GS, Nolen WA. Rapid and non-rapid cycling bipolar disorder: a meta-analysis of clinical studies. J Clin Psychiatry. 2003; 64(12):1483-94.

Kupka RW, Luckenbaugh DA, Post RM, Suppes T, Altshuler LL, Keck PE Jr, Frye MA, Denicoff KD, Grunze H, Leverich GS, McElroy SL, Walden J, Nolen WA. Comparison of rapid-cycling and non-rapid-cycling bipolar disorder based on prospective mood ratings in 539 outpatients. Am J Psychiatry. 2005; 162 (7):1273-80.

Kupka RW, Altshuler LL, Nolen WA, Suppes T, Luckenbaugh DA, Leverich GS, Frye MA, Keck PE Jr, McElroy SL, Grunze H, Post RM. Three times more days depressed than manic or hypomanic in both bipolar I and bipolar II disorder. Bipolar Disord. 2007; 9(5):531-5.

Lee S, Tsang A, Kessler RC, Jin R, Sampson N, Andrade L, Karam EG, Mora ME, Merikangas K, Nakane Y, Popovici DG, Posada-Villa J, Sagar R, Wells JE, Zarkov Z, Petukhova M. Rapid-cycling bipolar disorder: cross-national community study. Br J Psychiatry. 2010; 196(3):217-25.

Leverich GS, Altshuler LL, Frye MA, Suppes T, McElroy SL, Keck PE Jr, Kupka RW, Denicoff KD, Nolen WA, Grunze H, Martinez MI, Post RM. Risk of switch in mood polarity to hypomania or mania in patients with bipolar depression 
during acute and continuation trials of venlafaxine, sertraline, and bupropion as adjuncts to mood stabilizers. Am J Psychiatry. 2006: 163(2):232-9.

Li CT, Bai YM, Huang YL, Chen YS, Chen TJ, Cheng JY, Su TP. Association between antidepressant resistance in unipolar depression and subsequent bipolar disorder: cohort study. Br J Psychiatry. 2012; 200(1):45-51.

Lydiard RB, Culpepper L, Schioler H, Gustafsson U, Paulsson B. Quetiapine monotherapy as treatment for anxiety symptoms in patients with bipolar depression: a pooled analysis of results from 2 double-blind, randomized, placebo-controlled studies. Prim Care Companion J Clin Psychiatry. 2009; 11(5):215-25

MacQueen GM, Young LT. Bipolar II disorder: symptoms, course, and response to treatment. Psychiatr Serv. 2001; 52(3):358-61.

Magalhaes PV, Dean OM, Bush Al, Copolov DL, Malhi GS, Kohlmann K, Jeavons S, Schapkaitz I, Anderson-Hunt M, Berk M. N-acetyl cysteine add-on treatment for bipolar II disorder: a subgroup analysis of a randomized placebocontrolled trial. J Affect Disord. 2011; 129(1-3):317-20.

Maina G, Albert U, Bellodi L, Colombo C, Faravelli C, Monteleone P, Bogetto F, Cassano GB, Maj M. Health-related quality of life in euthymic bipolar disorder patients: differences between bipolar I and II subtypes. J Clin Psychiatry. 2007; 68(2):207-12

McElroy SL, Weisler RH, Chang W, Olausson B, Paulsson B, Brecher M, Agambaram V, Merideth C, Nordenhem A, Young AH. A double-blind, placebo-controlled study of quetiapine and paroxetine as monotherapy in adults with bipolar depression (EMBOLDEN II). J Clin Psychiatry. 2010; 71(2):163-74

McIntyre RS, Brecher M, Paulsson B, Huizar K, Mullen J. Quetiapine or haloperidol as monotherapy for bipolar mania-a 12-week, double-blind, randomised, parallel-group, placebo-controlled trial. Eur Neuropsychopharmacol. 2005; 15(5):573-85.

Merikangas KR, Akiskal HS, Angst J, Greenberg PE, Hirschfeld RM, Petukhova M, Kessler RC. Lifetime and 12-month prevalence of bipolar spectrum disorder in the National Comorbidity Survey replication. Arch Gen Psychiatry. 2007; 64(5):543-52

Merikangas KR, Jin R, He JP, Kessler RC, Lee S, Sampson NA, Viana MC, Andrade LH, Hu C, Karam EG, Ladea M, Medina-Mora ME, Ono Y, Posada-Villa J, Sagar $\mathrm{R}$, Wells JE, Zarkov Z. Prevalence and correlates of bipolar spectrum disorder in the world mental health survey initiative. Arch Gen Psychiatry. 2011; 68(3):241-51.

Montgomery SA, Asberg M. A new depression scale designed to be sensitive to change. Br J Psychiatry. 1979; 134:382-9.

Otto MW, Simon NM, Wisniewski SR, Miklowitz DJ, Kogan JN, Reilly-Harrington NA, Frank E, Nierenberg AA, Marangell LB, Sagduyu K, Weiss RD, Miyahara S, Thas ME, Sachs GS, Pollack MH. Prospective 12-month course of bipolar disorder in out-patients with and without comorbid anxiety disorders. Br J Psychiatry. 2006; 189:20-5.

Perugi G, Angst J, Azorin JM, Bowden C, Vieta E, Young AH. The bipolar-borderline personality disorders connection in major depressive patients. Acta Psychiatr Scand. 2013. doi:10.1111/acps.12083.

Rosa AR, Reinares M, Michalak EE, Bonnin CM, Sole B, Franco C, Comes M, Torrent C, Kapczinski F, Vieta E. Functional impairment and disability across mood states in bipolar disorder. Value Health. 2010; 13(8):984-8.

Seroquel Prescribing Information. Prescribing information. Wilmington, DE: AstraZeneca Pharmaceuticals LP; 2012

Simon GE, Bauer MS, Ludman EJ, Operskalski BH, Unutzer J. Mood symptoms, functional impairment, and disability in people with bipolar disorder: specific effects of mania and depression. J Clin Psychiatry. 2007; 68(8):1237-45.

Suppes T, Dennehy EB. Evidence-based long-term treatment of bipolar II disorder. J Clin Psychiatry. 2002; 63(Suppl 10):29-33.

Suppes T, Hirschfeld RM, Vieta E, Raines S, Paulsson B. Quetiapine for the treatment of bipolar II depression: analysis of data from two randomized, double-blind, placebo-controlled studies. World J Biol Psychiatry. 2008; 9(3):198-211.

Swartz HA, Thase ME. Pharmacotherapy for the treatment of acute bipolar II depression: current evidence. J Clin Psychiatry. 2011; 72(3):356-66.

Thase ME, Macfadden W, Weisler RH, Chang W, Paulsson B, Khan A, Calabrese JR. Efficacy of quetiapine monotherapy in bipolar I and II depression: a double-blind, placebo-controlled study (the BOLDER II study). J Clin Psychopharmacol. 2006; 26(6):600-9.

Thase ME, Jonas A, Khan A, Bowden CL, Wu X, McQuade RD, Carson WH, Marcus RN, Owen R. Aripiprazole monotherapy in nonpsychotic bipolar I depression: results of 2 randomized, placebo-controlled studies. J Clin Psychopharmacol. 2008; 28(1):13-20.

Valtonen H, Suominen K, Mantere O, Leppamaki S, Arvilommi P, Isometsa ET. Suicidal ideation and attempts in bipolar I and II disorders. J Clin Psychiatry. 2005; 66(11):1456-62.

Vazquez G, Tondo L, Baldessarini RJ. Comparison of antidepressant responses in patients with bipolar vs. unipolar depression: a meta-analytic review. Pharmacopsychiatry. 2011; 44(1):21-6.

Vieta E, Calabrese JR, Goikolea JM, Raines S, Macfadden W. Quetiapine monotherapy in the treatment of patients with bipolar I or II depression and a rapid-cycling disease course: a randomized, double-blind, placebo-controlled study. Bipolar Disord. 2007; 9(4):413-25.

Weisler RH, Nolen WA, Neijber A, Hellqvist A, Paulsson B. Continuation of quetiapine versus switching to placebo or lithium for maintenance treatment of bipolar I disorder (trial 144: a randomized controlled study). J Clin Psychiatry. 2011; 72(11):1452-64.

Yatham LN, Kennedy SH, Parikh SV, Schaffer A, Beaulieu S, Alda M, O'Donovan C, MacQueen G, Mclntyre RS, Sharma V, Ravindran A, Young LT, Milev R, Bond DJ, Frey BN, Goldstein Bl, Lafer B, Birmaher B, Ha K, Nolen WA, Berk M. Canadian Network for Mood and Anxiety Treatments (CANMAT) and International Society for Bipolar Disorders (ISBD) collaborative update of CANMAT guidelines for the management of patients with bipolar disorder: update 2013. Bipolar Disord. 2013; 15(1):1-44.

Young RC, Biggs JT, Ziegler VE, Meyer DA. A rating scale for mania: reliability, validity and sensitivity. Br J Psychiatry. 1978; 133:429-35.

Young AH, McElroy SL, Bauer M, Philips N, Chang W, Olausson B, Paulsson B, Brecher M. A double-blind, placebo-controlled study of quetiapine and lithium monotherapy in adults in the acute phase of bipolar depression (EMBOLDEN I). J Clin Psychiatry. 2010; 71(2):150-62.

Young AH, McElroy SL, Olausson B, Paulsson B. A randomised, placebo-controlled 52-week trial of continued quetiapine treatment in recently depressed patients with bipolar I and bipolar II disorder. World J Biol Psychiatry. 2012. doi:10.3109/15622975.2012.665177.

doi:10.1186/2194-7511-1-10

Cite this article as: Young et al:: Quetiapine monotherapy in bipolar II depression: combined data from four large, randomized studies. International Journal of Bipolar Disorders 2013 1:10.

\section{Submit your manuscript to a SpringerOpen ${ }^{\odot}$ journal and benefit from:}

- Convenient online submission

- Rigorous peer review

- Immediate publication on acceptance

- Open access: articles freely available online

- High visibility within the field

- Retaining the copyright to your article

Submit your next manuscript at $>$ springeropen.com 